\title{
Clinical and biological factors associated with irreversible airway obstruction in adult asthma
}

\author{
Sophie Graff ${ }^{\mathrm{a}, *}$, Noëmie Bricmont ${ }^{\mathrm{b}}$, Catherine Moermans ${ }^{\mathrm{a}}$, Monique Henket ${ }^{\mathrm{a}}$, Virginie Paulus ${ }^{\mathrm{a}}$, \\ Françoise Guissard ${ }^{a}$, Renaud Louis ${ }^{a}$, Florence Schleich ${ }^{\mathrm{a}}$

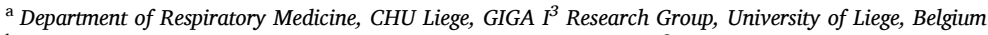 \\ ${ }^{\mathrm{b}}$ Department of Pediatrics, division of respirology, CHU Liege, GIGA $I^{3}$ Research Group, University of Liege, Belgium
}

\section{A R T I C L E I N F O}

\section{Keywords:}

Asthma

Airway inflammation

Airflow obstruction

Eosinophils

Lung diseases

\begin{abstract}
A B S T R A C T
Background and objective: Airway remodeling, as many other factors, may lead to lung function decline and irreversible airflow obstruction (IRAO) in asthma. This study was undertaken in order to highlight predictors of incomplete reversibility of airflow obstruction in adult asthmatics to identify patients with poorer prognosis and improve their care, and decrease morbidity.

Methods: A retrospective study was conducted in 973 asthmatics recruited from the University Asthma Clinic of Liege. Patients with IRAO (post-BD $\mathrm{FEV}_{1} / \mathrm{FVC}<0.7 \& \mathrm{FEV}_{1}<80 \%$ predicted) were compared to patients with reversible airway obstruction (RAO) (post-BD $\mathrm{FEV}_{1} / \mathrm{FVC} \geq 0.7 \& \mathrm{FEV}_{1} \geq 80 \%$ predicted). TGF- $\beta$ was measured in sputum supernatant of 85 patients.

Results: Seventeen percent of asthmatics presented with IRAO. These patients were significantly older, more smokers, with a lower proportion of female, a longer disease duration, were more poorly controlled with a lower quality of life. This sub-population of asthmatics also showed more often elevated blood and sputum eosinophils and neutrophils, and higher exacerbation and hospitalisation rates in the previous year. The multivariable analysis revealed male gender, longer disease duration, cigarette smoking, ACQ score, sputum eosinophils and neutrophils, ICS dose and OCS maintenance, BMI, and asthma onset as variables independently linked to IRAO. Total TGF- $\beta$ levels appeared higher in patients with IRAO $(n=38)$ compared to patients with RAO $(n=47)$. Conclusion: These data show that risk factors for IRAO are male gender, smoking, a longer disease duration, uncontrolled asthma, eosinophilic or neutrophilic airway inflammation, lower BMI, and later asthma onset. Moreover, TGF- $\beta$ levels are higher in IRAO.
\end{abstract}

Sophie GraffFlorence SchleichNoëmie BricmontCatherine MoermansMonique HenketVirginie PaulusFrançoise GuissardRenaud Louis

\section{Introduction}

Asthma is a chronic inflammatory airway disease commonly associated with reversible airway obstruction. On average, asthma patients have lower lung function than healthy individuals [1] and their lung function $\left(\mathrm{FEV}_{1}\right)$ decline can be greater over time [2,3]. Most of patients with mild to moderate asthma can be controlled with regular medication. However, asthma patients are at risk of developing structural changes resulting in persistent airflow limitations [1,2,4] despite anti-inflammatory therapies. The features of remodeling include subepithelial reticular basement membrane (RBM) thickening, hypertrophy and hyperplasia of airway smooth muscle (ASM) cells, angiogenesis and goblet cell hyperplasia [5], responsible for airway narrowing. A small proportion of non-smoking asthmatics present with irreversible airway obstruction (IRAO) which can be considered another form of lung function decline in asthma [6]. IRAO is defined as a significantly reduced ratio between $\mathrm{FEV}_{1}$ and FVC after bronchodilation $[7,8]$.

Studies on risk factors and prevalence of IRAO in asthma are limited. Moreover, no consensus is reached on a definition of IRAO [9]. Yet, predictors for IRAO including smoking [10], longer disease duration $[10,11]$, male gender $[10,12]$, aspirin sensitivity [13], greater airway hyperresponsiveness (AHR) [14], less chronic rhinitis [15], adult onset [14], and FeNO $[9,10,14]$ have been reported.

Persistent airway obstruction partly relates to airway remodeling the histological substrate of which is a sub-epithelial fibrosis [16] [-] [18]. TGF- $\beta$ is known to be the prominent mediator in airway fibrosis but has been poorly investigated in the context of asthma with fixed airway

\footnotetext{
* Corresponding author. Department of Respiratory Medicine, CHU Sart-Tilman, GIGA +4; CHU - B34, Avenue de l'Hôpital, 11, 4000, Liège, Belgium.

E-mail address: sgraff@uliege.be (S. Graff).
} 


\begin{tabular}{|llll|}
\hline Abreviation list & $\mathrm{FEV}_{1}$ & forced expiratory volume in $1 \mathrm{~s}$ \\
ACQ & asthma control questionnaire & $\mathrm{FVC}$ & functional vital capacity \\
ACT & asthma control test & ICS & inhaled corticosteroids \\
AQLQ & asthma quality of life questionnaire & IgE & immunoglobulin E \\
ATS & American Thoracic Society & IRAO & irreversible airway obstruction \\
BD & bronchodilation & LABA & long-acting $\beta 2$ agonists \\
BEC & blood eosinophil count & LAMA & long-acting muscarinic antagonists \\
BNC & blood neutrophil count & LTRA & antileukotrienes \\
CRP & C-reactive protein & OCS & oral corticosteroids \\
ERS & European Respiratory Society & RAO & reversible airway obstruction \\
FeNO & fractional exhaled nitric oxide & TGF- $\beta$ & transforming growth factor beta \\
& & & \\
\hline
\end{tabular}

obstruction [19]. The active TGF- $\beta$ present at steady state is the biologically active form while total TGF- $\beta 1$ is the active form plus the latent TGF- $\beta$ liberated by acidification. Assessing both the active and latent TGF- $\beta$ simultaneously is useful to assess how TGF- $\beta$ is involved in the pathogenesis of the disease.

This study was undertaken in order to compare patients with irreversible airway obstruction to patients with reversible airway obstruction, and highlight predictors of incomplete reversibility of airflow obstruction in adult asthmatics to identify patients with poorer prognosis and improve their care, and decrease morbidity.

\section{Methods}

A retrospective study was conducted on adult asthmatics at stable state with post-bronchodilation (BD) spirometry measurements and successful sputum induction recruited from the University Asthma Clinic of Liege, Belgium.

Patients were allocated in two distinct groups based on post-BD $\mathrm{FEV}_{1} / \mathrm{FVC}$ and post-BD $\mathrm{FEV}_{1}$ measurements. Patients with IRAO $\left(\mathrm{FEV}_{1} / \mathrm{FVC}<0.7\right.$ and $\mathrm{FEV}_{1}<80 \%$ predicted) were compared with patients with reversible airway obstruction (RAO) (post-BD $\mathrm{FEV}_{1} / \mathrm{FVC}$ $\geq 0.7$ and $\mathrm{FEV}_{1} \geq 80 \%$ predicted). Patients that did not fit into one of these categories (i.e. $\mathrm{FEV}_{1} / \mathrm{FVC}<0.7$ and $\mathrm{FEV}_{1} \geq 80 \%$ predicted or $\mathrm{FEV}_{1} / \mathrm{FVC} \geq 0.7$ and $\mathrm{FEV}_{1}<80 \%$ predicted) were not included (Fig. 1).

All procedures were performed in the context of clinical practice and the retrospective data collection was conducted with approval from the ethics committee of CHU Liège (2005/181) in accordance to the Helsinki Declaration.

Quality of Life was assessed using self-administered Asthma Quality of Life Questionnaire (AQLQ) [20] and Asthma control by the Juniper Asthma Control Questionnaire (ACQ7) [21] and an Asthma Control Test (ACT) [22]. Subjects were characterized as atopic if they had at least one

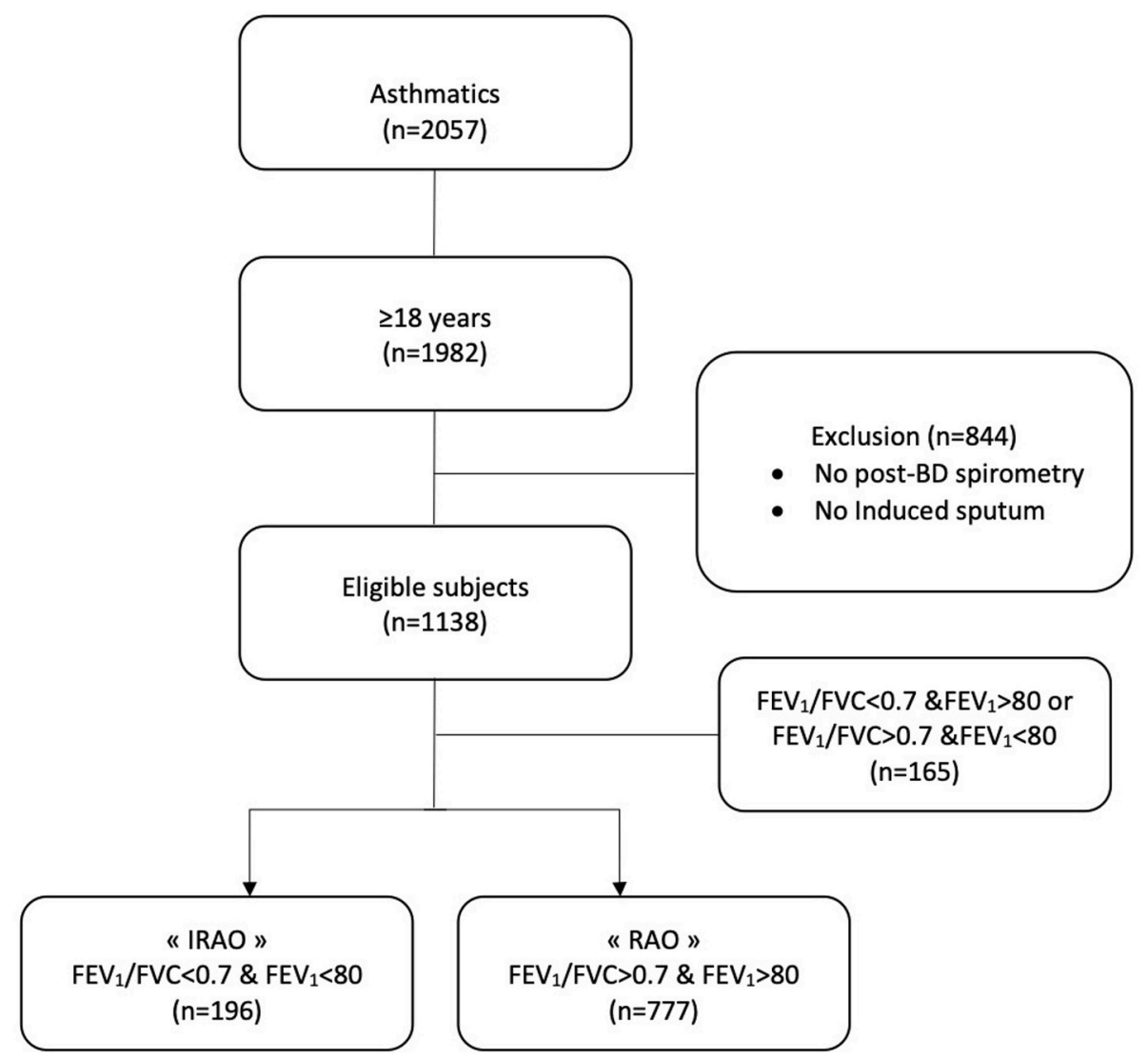

Fig. 1. Study design: $\mathrm{FEV}_{1}$, forced expiratory volume in $1 \mathrm{~s}$ (\% predicted); FVC, Forced vital capacity; post-BD, post-bronchodilation; RAO, Reversible airway obstruction; IRAO, irreversible airway obstruction. 
positive specific Immunoglobulin E (IgE) test (0.35 kU.L-1; Phadia, Groot-Bijgaarden, Belgium) for at least one common aeroallergen.

Patients underwent Fractional exhaled Nitric Oxide (FeNO) measurements at flow rate of $50 \mathrm{~mL} / \mathrm{s}$ according to the ERS/ATS recommendations [23] (NIOX, Aerocrine, Sweden) followed by spirometry with bronchodilation, sputum induction on the same day. Sputum induction and processing were performed as previously described [24] using the whole expectorate.

Cell counts were estimated on samples centrifuged (Cytospin) and stained with Hemacolor ${ }^{\circledR}$ Staining set after counting 500 non-squamous cells (Merck chemical, Overijste, Belgium). Sputum cytology was analyzed and 4 phenotypes were defined: the eosinophilic phenotype with $3 \%$ sputum eosinophil count (and $<76 \%$ neutrophil count), the neutrophilic phenotype with $76 \%$ sputum neutrophil count (and $<3 \%$ eosinophil count), and the mixed granulocytic phenotype being a combination of the above [25]. The paucigranulocytic phenotype was defined as an inflammatory cell count below these thresholds.

Routine laboratory of the University Hospital of Liege performed blood cell count and analysis of C-reactive protein (CRP), fibrinogen, and total IgE levels (ImmunoCAP system (Phadia AB, Uppsala; Sweden)).

Inhaled corticosteroids (ICS) dosages and treatment with antileukotrienes (LTRA), Long-acting muscarinic antagonists (LAMA), Longacting beta- 2 agonists (LABA), Anti-IgE, anti-IL5 and oral corticosteroids (OCS) were recorded and used in the analyses.

In a subpopulation of 85 non-smoking, OCS naïve patients, with either an eosinophilic or a neutrophilic inflammatory phenotype, both active (present at steady state) and total (present at steady state \& latent form liberated after acidification) Transforming growth factor beta (TGF- $\beta$ ) were measured in sputum supernatant [19]. Briefly, transformed mink lung cells (TMLC, gift of Daniel Rifkin, New York University medical center, NY) stably transfected with plasminogen activator inhibitor-1 (PAI-1) promoter fused to the firefly luciferase reporter gene, were cultured with sputum supernatant. To activate the latent TGF- $\beta$, the supernatants were incubated with $1 \mathrm{~N} \mathrm{H} \mathrm{Cl}$ for $10 \mathrm{~min}$ and neutralized by $1.2 \mathrm{~N} \mathrm{NaOH} / 0.5 \mathrm{M}$ HEPES. The TMLC were cultured in DMEM with $10 \%$ of FBS and were plated at the density of 15,000 cells/well in a 96-well plate. The supernatants were then added (final dilution 4X) and incubated 16-20 h. Recombinant human TGF- $\beta 1$ (4 $\mathrm{ng} / \mathrm{ml}, \mathrm{R} \& \mathrm{D}$ Systems, Minneapolis, USA) were used as positive controls. Each condition was done with and without anti-hTGF- $\beta 1$ antibody ( 1 $\mu \mathrm{g} / \mathrm{ml}, \mathrm{R} \& \mathrm{D}$ Systems, Minneapolis, USA). Each sample was done in triplicate and results were expressed as relative light units.

\subsection{Statistical methods}

Variables independently associated to IRAO were identified by logistic regression. Independent variables such as atopy, gender, cigarette smoking (Pack Year), Body Mass Index, asthma onset, disease duration, FeNO, ACQ score, ICS dose, OCS maintenance, hospitalizations and exacerbations during the last 12 months, blood eosinophil (BEC) and blood neutrophil (BNC) counts $\left(/ \mathrm{mm}^{3}\right)$, sputum eosinophils and neutrophils counts (\%) were included in the univariate model. $\mathrm{FEV}_{1} / \mathrm{FVC}$ $<70$ and $\mathrm{FEV}_{1}<80 \%$ predicted was used as the dependent variable. A multivariable analysis was done including all independent variables. In order to test the robustness of the analysis, the same logistic regression analysis was performed with the never-smoking patients. Factors affecting $\mathrm{FEV}_{1} / \mathrm{FVC}$ ratio were evaluated with a conventional linear regression using the same independent variables as in the logistic regression. $\mathrm{FEV}_{1} / \mathrm{FVC}$ ratio was used as the dependent variable.

We constructed receiver-operating characteristic (ROC) curves for all continuous variables independently associated with IRAO to determine the cut-off which best identified IRAO ( $\mathrm{FEV}_{1} / \mathrm{FVC}<0.7$ and $\mathrm{FEV}_{1}<80 \%$ predicted) in asthma. Optimal cutoff points were determined by the method of the nearest point to $(0,1)$. A $p$ value $<0.05$ was considered statistically significant. Statistical analysis was done using STATA version 14.0 (Statistical Software, College Station, TX: StataCorp LP).

\section{Results}

\subsection{IRAO patients' characteristics}

In our database, 1138 patients recruited between January 2005 and March 2019 had post-BD spirometry measurement and successful sputum induction. Out of these, 973 of these patients were allocated in two distinct groups. A hundred and ninety-six asthmatics (17\% of total population, 196/1138) presented with IRAO $\left(\mathrm{FEV}_{1} / \mathrm{FVC}<0.7\right.$ \& $\mathrm{FEV}_{1}<80 \%$ predicted) and 777 patients (68\% of the total population $777 / 1138$ ) with RAO ( $\mathrm{FEV}_{1} / \mathrm{FVC} \geq 0.7 \& \mathrm{FEV}_{1}>80 \%$ predicted). Demographic, clinical and inflammatory characteristics of these patients are presented in Table.1. Patients with IRAO were significantly more often male $(\mathrm{p}=0.034)$, older $(\mathrm{p}<0.0001)$, more (ex)smokers $(\mathrm{p}<$ 0.0001 ), with a longer disease duration $(\mathrm{p}<0.0001)$, were more poorly controlled (ACT and ACQ scores) ( $p<0.0001)$ with a lower quality of life (AQLQ score) $(\mathrm{p}<0.0001)$, treated with higher ICS daily dose $(\mathrm{p}<$ $0.0001)$ and more often with OCS maintenance $(\mathrm{p}<0.0001)$, LABA ( $<$ 0.0001 ), LAMA ( $p<0.0001$ ), and LTRA ( $p=0.001)$. This subpopulation of asthmatics also presented more often with diffuse (blood and sputum) eosinophilic and neutrophilic inflammation ( $\mathrm{p}<0.0001)$, and significantly higher $\operatorname{IgE}(\mathrm{p}=0.007)$ and markers of inflammation (fibrinogen ( $\mathrm{p}=0.008)$, CRP $(\mathrm{p}=0.02)$ and blood leukocytes $(\mathrm{p}<$ $0.0001)$ ). Exacerbation and hospitalisation rates in the previous year ( $\mathrm{p}$ $<0.001$ ) were also higher in this sub-population.

\subsection{Factors associated with IRAO}

The univariate model of the logistic regression (Table.2) showed a positive association between $\mathrm{FEV}_{1} / \mathrm{FVC}<0.7 \& \mathrm{FEV}_{1}<80 \%$ predicted and male gender (OR:0.71 (95\%CI 0.52-0.97)), Pack-Year (1.77 (1.44-2.16)), disease duration (1.02 (1.02-1.04)), ACQ score (3.25 (2.71-3.91)), ICS dose (2.07 (1.78-2.42)), OCS maintenance 4.75 (3.12-7.22)), exacerbation (1.39; (1.24-1.56)) and hospitalisation rate (2.35 (1.70-3.25)) in the previous year, BNC $\left(/ \mathrm{mm}^{3}\right)(1.0(1.0-1.0))$, BEC (1.41 (1.23-1.63)), and sputum eosinophil count $\left(/ \mathrm{mm}^{3}\right)(1.36$ (1.18-1.56)).

The multivariable analysis revealed male gender (OR female: 0.38 (95\%CI 0.20-0.72)), pack-year (1.76 (1.19-2.61)), disease duration (1.06 (1.04-1.09)), ACQ score (2.63 (1.94-3.56)), sputum eosinophils (1.73 (1.22-2.47)), sputum neutrophils (1.53 (1.15-2.04)), ICS daily dose (1.60 (1.21-2.13)), BMI (0.70 (0.54-0.92)), age of onset (2.20 (1.27-3.83), and OCS therapy (2.67 (1.11-6.39)) (Table.2).

\subsection{IRAO in never-smokers}

In the never-smoking patients $(\mathrm{n}=521)$ (Supplementary Table S1), seventy-six (15\%) presented with IRAO compared to 445 (85\%) with RAO. Results of the multivariable logistic regression showed ACQ (OR:2.27 (95\%CI:1.47-3.48)), sputum eosinophils (1.85 (1.08-3.14)), disease duration (1.06 (1.02-1.09)) were independently associated with the outcome.

\subsection{Factors affecting $F E V_{1} / F V C$ ratio}

The univariate analysis of the linear regression analysis (Table.3) revealed a negative association between $\mathrm{FEV}_{1} / \mathrm{FVC}$ ratio and cigarette smoking (Pack Year) (Reg. coeff:-0.17 (95\%CI:-0.21 to -0.13)), ACQ score $(-4.26(-4.80$ to -3.71$)$, BEC $(-0.0017(-0.0031$ to -0.0002$)$, BNC $(-0.0004(-0.0006$ to -0.0002$))$, sputum eosinophil count (\%) ( $-0.13(-0.17$ to -0.09$)$ ), ICS daily dose $(-3.04(-3.63$ to -2.43$))$, OCS maintenance therapy $(-8.30(-10.6$ to -5.99$)$, exacerbation $(-1.54$ $(-2.07$ to -0.99$)$ ), and hospitalisation $(-4.35(-5.74$ to -2.96$))$ rates over the last 12 months, and disease duration $(-0.15(-0.19$ to -0.096$))$. A 
Table 1

Demographic, functional, inflammatory, and treatment characteristics.

\begin{tabular}{|c|c|c|c|}
\hline Characteristics & RAO & IRAO & p-value \\
\hline N. (\%) & $777 / 1138(68)$ & 196/1138 (17) & \\
\hline Women (\%) & $478(62)$ & $104(53)$ & 0.034 \\
\hline Age (yr) & $48 \pm 16$ & $56 \pm 13$ & $<0.0001$ \\
\hline Height $(\mathrm{cm})$ & $168 \pm 9$ & $169 \pm 10$ & 0.6043 \\
\hline Weight (Kg) & $75 \pm 16$ & $75 \pm 16$ & 0.9189 \\
\hline BMI $\left(\mathrm{kg} / \mathrm{m}^{2}\right)$ & $27 \pm 5$ & $26 \pm 5$ & 0.6017 \\
\hline Atopy (Y) (\%) & $416(57)(n=730)$ & $95(52)(n=182)$ & 0.278 \\
\hline Smoking status: (\%) & $(\mathrm{n}=775)$ & $(\mathrm{n}=192)$ & $<0.0001$ \\
\hline Never Smokers & $443(57)$ & $72(38)$ & \\
\hline Current Smokers & $140(18)$ & $40(21)$ & \\
\hline Ex-Smokers & $192(25)$ & $80(42)$ & \\
\hline Pack-years: & & & $<0.0001$ \\
\hline Current smokers & $14(7-26)$ & $27(11-41)$ & \\
\hline Ex-smokers & $14(6-26)$ & $19(8-36)$ & \\
\hline Age of onset (yr) & $32 \pm 22(\mathrm{n}=585)$ & $32 \pm 21(n=158)$ & 0.9756 \\
\hline Disease duration (yr) & $16 \pm 16(n=585)$ & $24 \pm 19(n=158)$ & $<0.0001$ \\
\hline \multicolumn{4}{|l|}{ Pre-BD FEV } \\
\hline (L) & $2.854 \pm 0.809$ & $1.559 \pm 0.588$ & $<0.0001$ \\
\hline (\% pred) & $94 \pm 14$ & $54 \pm 14$ & $<0.0001$ \\
\hline \multicolumn{4}{|l|}{ Post-BD FEV 1} \\
\hline (L) & $3.04 \pm 0.84$ & $1.69 \pm 0.60$ & $<0.0001$ \\
\hline (\% pred) & $100 \pm 12$ & $58 \pm 14$ & $<0.0001$ \\
\hline \multicolumn{4}{|l|}{ Post-BD FVC } \\
\hline (\% pred) & $103 \pm 13$ & $81 \pm 16$ & $<0.0001$ \\
\hline \multicolumn{4}{|l|}{ Post-BD FEV 1 /FVC } \\
\hline (\% pred) & $81 \pm 7$ & $58 \pm 8$ & $<0.0001$ \\
\hline PC20M (mg/mL) & $\begin{array}{c}1.54(0.18-13.13) \\
(n=549)\end{array}$ & $\begin{array}{c}0.64(0.44-0.93) \\
(\mathrm{n}=17)\end{array}$ & 0.4120 \\
\hline Reversibility (\%) & $7.00 \pm 8.41$ & $9.53 \pm 14.07$ & 0.0013 \\
\hline ACT score & $\begin{array}{c}16.4 \pm 5.1 \\
(\mathrm{n}=767)\end{array}$ & $\begin{array}{c}12.8 \pm 5.2 \\
(n=188)\end{array}$ & $<0.0001$ \\
\hline ACQ score & $\begin{array}{c}1.62 \pm 1.02 \\
(n=749)\end{array}$ & $\begin{array}{c}3.08 \pm 1.14 \\
(\mathrm{n}=185)\end{array}$ & $<0.0001$ \\
\hline AQLQ score & $\begin{array}{c}4.73 \pm 1.29 \\
(n=766)\end{array}$ & $\begin{array}{c}3.81 \pm 1.29 \\
(n=195)\end{array}$ & $<0.0001$ \\
\hline FeNO (ppb) & $\begin{array}{c}23(13-44) \\
(\mathrm{n}=762)\end{array}$ & $\begin{array}{c}22(13-44) \\
(n=187)\end{array}$ & 0.6642 \\
\hline \multicolumn{4}{|l|}{ Sputum eosinophil count } \\
\hline$(/ \mu \mathrm{L})$ & $\begin{array}{c}20.94(0.68- \\
150.53)\end{array}$ & $\begin{array}{c}77.34(8.96- \\
788.76)\end{array}$ & $<0.0001$ \\
\hline $\begin{array}{l}\text { Sputum neutrophil count } \\
\text { (\% of non-squamous cells) }\end{array}$ & $57.0(35.4-77.2)$ & $63.1(35.4-83.0)$ & 0.0698 \\
\hline$(/ \mu \mathrm{L})$ & $\begin{array}{l}711.5(260.0- \\
2060.0)\end{array}$ & $\begin{array}{l}1297.0(377.0- \\
3626.0)\end{array}$ & 0.0002 \\
\hline Inflammatory phenotypes: & & & $<0.0001$ \\
\hline Paucigranulocytic & $315(41 \%)$ & $34(17 \%)$ & \\
\hline Eosinophilic & $252(32 \%)$ & $97(50 \%)$ & \\
\hline Neutrophilic & $167(21 \%)$ & $55(28 \%)$ & \\
\hline Mixed granulocytic & $43(6 \%)$ & $10(5 \%)$ & \\
\hline Total serum IgE (kU/L) & $\begin{array}{c}104(34-295) \\
(\mathrm{n}=733)\end{array}$ & $\begin{array}{c}139(64-384) \\
(\mathrm{n}=177)\end{array}$ & 0.0072 \\
\hline $\begin{array}{l}\text { Blood leukocytes (x } 10^{3} / \\
\mu \mathrm{L})\end{array}$ & $\begin{array}{c}7.10(5.88-8.39) \\
(n=761)\end{array}$ & $\begin{array}{c}8.43(6.76-10.13) \\
(n=186)\end{array}$ & $<0.0001$ \\
\hline Fibrinogen (g/L) & $\begin{array}{c}3.23(2.71-3.72) \\
\quad(n=734)\end{array}$ & $\begin{array}{c}3.38(2.87-3.93) \\
\quad(n=167)\end{array}$ & 0.0080 \\
\hline CRP (mg/L) & $\begin{array}{c}1.90(0.84-4.54) \\
\quad(n=734)\end{array}$ & $\begin{array}{c}2.44(1.15-6.26) \\
\quad(n=167)\end{array}$ & 0.0190 \\
\hline Blood eosinophils & $(n=761)$ & $(n=185)$ & \\
\hline (\%) & $2.4(1.4-3.9)$ & $3.0(1.4-5.6)$ & 0.0031 \\
\hline$(/ \mu \mathrm{L})$ & $168(92-283)$ & $249(119-433)$ & $<0.0001$ \\
\hline Blood neutrophils & $(\mathrm{n}=761)$ & $(\mathrm{n}=185)$ & \\
\hline (\%) & $53.9(47.8-60.8)$ & $59.1(51.7-65.9)$ & $<0.0001$ \\
\hline$(/ \mu \mathrm{L})$ & $3761(2935-4910)$ & $\begin{array}{c}4766(3641- \\
6374)\end{array}$ & $<0.0001$ \\
\hline ICS dose $(\mu \mathrm{g} / \mathrm{d})$ & $4(0-1000)$ & $1500(800-2000)$ & $<0.0001$ \\
\hline ICS category: (\%) & & & $<0.0001$ \\
\hline Steroid naïve & 347 (47) & $29(11)$ & \\
\hline Low dose & $99(13)$ & $14(7)$ & \\
\hline Medium dose & $135(18)$ & $40(21)$ & \\
\hline High dose & $162(22)$ & $107(56)$ & \\
\hline LABA, N (\%) & $403(52)(n=774)$ & $167(86)(n=195)$ & $<0.0001$ \\
\hline LTRA, N (\%) & $175(23)$ & $67(34)$ & 0.001 \\
\hline LAMA, N (\%) & $13(2)(n=773)$ & $53(27)(n=195)$ & $<0.0001$ \\
\hline
\end{tabular}

Table 1 (continued)

\begin{tabular}{cccc}
\hline Characteristics & RAO & IRAO & p-value \\
\hline OCS therapy, N (\%) & $55(7)(\mathrm{n}=773)$ & $52(27)(\mathrm{n}=195)$ & $<0.0001$ \\
$\quad$ Biotherapies: & $8(1)$ & $5(3)$ & 0.055 \\
Anti-IgE & $11(1)$ & $6(3)$ & \\
Anti-IL5 & $0(0-1)(\mathrm{n}=664)$ & $1(0-2)(\mathrm{n}=160)$ & $<0.0001$ \\
Hospitalizations in \\
$\quad$ previous year \\
$\begin{array}{c}\text { Exacerbations in previous } \\
\text { year }\end{array}$ & $0(0-0)(\mathrm{n}=676)$ & $0(0-1)(\mathrm{n}=170)$ & $<0.0001$ \\
& & &
\end{tabular}

Comparison between RAO (Post-BD $\mathrm{FEV}_{1} / \mathrm{FVC} \geq 0.7 \&$ post-BD $\mathrm{FEV}_{1} \geq 80$ predicted) and IRAO Post-BD $\mathrm{FEV}_{1} / \mathrm{FVC}<0.7$ \& Post-BD $\mathrm{FEV}_{1}<80$ predicted) asthmatics.

Data are presented as mean \pm SD or median and IQR. PC20 M is presented as geometric mean (min-max). BMI, Body Mass Index; BD, bronchodilation; $\mathrm{FEV}_{1}$, forced expiratory volume in 1s; FVC, Forced vital capacity; PC20 M, provocative concentration of metacholine causing a $20 \%$ fall in $\mathrm{FEV}_{1}$; ACT, Asthma control test; ACQ, Asthma Control Questionnaire; AQLQ, Asthma Quality of Life Questionnaire; FeNO, fractional exhaled nitric oxide; ppb, parts per billion; CRP, C reactive protein; ICS, inhaled corticosteroid; LABA, Long-acting B2-agonist; LTRA, Leucotriene receptor antagonist; LAMA, Long-acting muscarinic antagonist; OCS, oral corticosteroid; Low-dose ICS: $<500 \mu \mathrm{g} / \mathrm{d}$; moderate-dose ICS : $>500-1000 \mu \mathrm{g} / \mathrm{d}$; high-dose ICS : $>1000 \mu \mathrm{g} / \mathrm{d}$ beclomethasone dipropionate chlorofluorocarbon.

positive association was observed for the female gender $(2.48$ (0.98-3.98)). The multivariable analysis (Table.3) showed that variables independently associated to $\mathrm{FEV}_{1} / \mathrm{FVC}$ ratio were Body Mass Index (0.42 (0.26-0.58)), smoking (Pack-Year) $(-0.11(-0.16$ to -0.06$))$, female gender (3.26 (1.61-4.90)), ACQ $(-2.57(-3.34$ to -1.81$))$, BNC $(-0.0002(-0.001$ to -0.00003$))$, ICS daily dose $(-1.11(-1.87$ to $-0.35)$ ), hospitalisation rate over the last 12 months $(-2.04(-3.81$ to $-0.26)$ ), disease duration $(-0.23(-0.29$ to -0.17$)$ ), sputum eosinophil count $(-0.08(-0.14$ to -0.02$))$, and age of onset $(-3.39(-4.88$ to $-1.90)$ ).

\subsection{Roc curves}

Constructing a ROC curve, revealed that the ACQ score was able to identify IRAO with the best cut-off point of 2.36 providing a $\% 72$ sensitivity and $77 \%$ specificity (AUC $0.8260, \mathrm{p}<0.0001$, Fig. 2). We also tested other potential markers for IRAO, such as FeNO, disease duration, sputum neutrophil count, sputum eosinophil count, and BNC, but found AUC of $0.4898(\mathrm{p}=0.6642), 0.6326(\mathrm{p}<0.0001), 0.6133(\mathrm{p}$ $=0.0698), 0.5419(\mathrm{p}<0.0001)$, and $0.6542(\mathrm{p}<0.0001)$ respectively. These markers are not able to discriminate between IRAO and RAO.

\subsection{TGF- $\beta$ activation levels}

TGF- $\beta$ levels were measured in 85 asthmatics. Thirty-eight patients with IRAO were compared to 47 patients with RAO. In the IRAO group, 21 patients presented with eosinophilic asthma and 17 were classified as having neutrophilic asthma. Twenty-four patients were eosinophilic and 23 were neutrophilic in the RAO group. These 85 patients presented with the same characteristics as the total population in this study (Supplementary Table S2).

Active TGF- $\beta$ levels were not different in IRAO and RAO groups ( $\mathrm{p}=$ 0.2775 ). Total TGF- $\beta$ levels were significantly higher in IRAO compared to RAO group ( $\mathrm{p}=0.0363$ ) (Fig. 3 \& Supplementary Table S3).

\section{Discussion}

In a general population of asthmatics, we found that risk factors for fixed airway obstruction are: male gender, smoking (pack-year), longer disease duration, poor asthma control, sputum eosinophils and neutrophils, ICS daily dose, BMI, later onset, and OCS therapy. Focusing on non-smoking patients we confirmed that ACQ score, disease duration 
Table 2

Factors associated with IRAO. Results of the logistic regression $* \mathrm{~N}=973$.

\begin{tabular}{|c|c|c|c|c|c|c|}
\hline \multirow[t]{3}{*}{ IRAO } & \multicolumn{6}{|c|}{ Total population } \\
\hline & \multicolumn{3}{|c|}{ UNIVARIATE } & \multicolumn{3}{|c|}{ MULTIVARIABLE } \\
\hline & OR & $95 \% \mathrm{CI}$ & P-value & OR & $95 \% \mathrm{CI}$ & P-value \\
\hline Gender (M) & 0.71 & $0.52-0.97$ & 0.031 & 0.38 & $0.20-0.72$ & 0.003 \\
\hline BMI & 1.05 & $0.91-1.21$ & 0.505 & 0.70 & $0.54-0.92$ & 0.010 \\
\hline Age of onset & 0.99 & $0.81-1.21$ & 0.911 & 2.20 & $1.27-3.83$ & 0.005 \\
\hline Pack-Year & 1.77 & $1.44-2.16$ & $<0.0001$ & 1.76 & $1.19-2.61$ & 0.005 \\
\hline Atopy & 0.82 & $0.60-1.14$ & 0.245 & 0.84 & $0.43-1.64$ & 0.617 \\
\hline ACQ & 3.25 & $2.71-3.91$ & $<0.0001$ & 2.63 & $1.94-3.56$ & $<0.0001$ \\
\hline ICS & 2.07 & $1.78-2.42$ & $<0.0001$ & 1.60 & $1.21-2.13$ & 0.001 \\
\hline OCS & 4.75 & $3.12-7.22$ & $<0.0001$ & 2.67 & $1.11-6.39$ & 0.028 \\
\hline BEC & 1.41 & $1.23-1.63$ & $<0.0001$ & 1.12 & $0.82-1.53$ & 0.468 \\
\hline BNC & 1.0 & $1.0-1.0$ & 0.023 & 1.00 & $0.99-1.00$ & 0.272 \\
\hline SEC & 1.36 & $1.18-1.56$ & $<0.0001$ & 1.73 & $1.22-2.47$ & 0.002 \\
\hline SNC & 1.10 & $0.96-1.26$ & 0.148 & 1.53 & $1.15-2.04$ & 0.004 \\
\hline FeNO & 0.97 & $0.83-1.13$ & 0.681 & 0.74 & $0.54-1.02$ & 0.067 \\
\hline Exacerbations & 1.39 & $1.24-1.56$ & $<0.0001$ & 0.97 & $0.78-1.20$ & 0.776 \\
\hline Disease duration & 1.02 & $1.02-1.04$ & $<0.0001$ & 1.06 & $1.04-1.09$ & $<0.0001$ \\
\hline Hospitalizations & 2.35 & $1.70-3.25$ & $<0.0001$ & 1.12 & $0.60-2.07$ & 0.720 \\
\hline
\end{tabular}

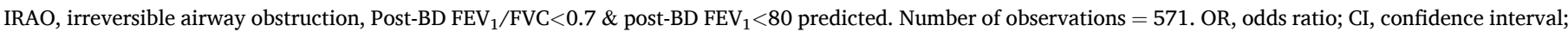

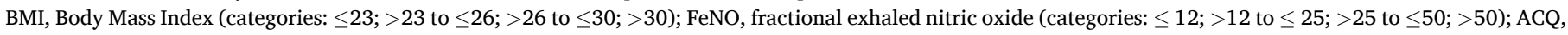

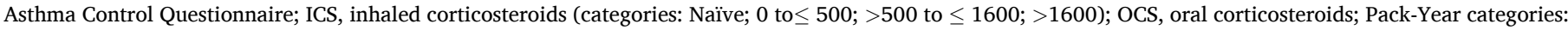

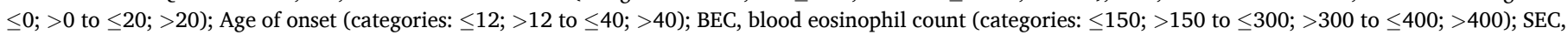
sputum eosinophil count (categories: $\leq 0.2$; $>0.2$ to $\leq 3$; $>3$ to $\leq 10$; $>10$ ); SNC, sputum neutrophil count (categories: $\leq 38$; $>38$ to $\leq 59$; $>59$ to $\leq 76$; $>76$ ).

Table 3

Results of the linear regression model $* \mathrm{~N}=973$.

\begin{tabular}{|c|c|c|c|c|c|c|}
\hline \multirow[t]{3}{*}{$\mathrm{FEV}_{1} / \mathrm{FVC}$} & \multicolumn{6}{|c|}{ Total population* } \\
\hline & \multicolumn{3}{|c|}{ UNIVARIATE } & \multicolumn{3}{|c|}{ MULTIVARIABLE } \\
\hline & Coeff. & $95 \% \mathrm{CI}$ & P-value & Coeff. & $95 \% \mathrm{CI}$ & P-value \\
\hline Gender (M) & 2.48 & 0.98 to 3.98 & 0.001 & 3.26 & 1.61 to 4.90 & $<0.0001$ \\
\hline BMI & 0.08 & -0.07 to 0.23 & 0.308 & 0.42 & 0.26 to 0.58 & $<0.0001$ \\
\hline Age of onset & 0.02 & -0.92 to 0.95 & 0.970 & -3.39 & -4.88 to -1.90 & $<0.0001$ \\
\hline Pack-Year & -0.17 & -0.21 to -0.13 & $<0.0001$ & -0.11 & -0.16 to -0.06 & $<0.0001$ \\
\hline Atopy & 1.04 & -0.49 to 2.57 & 0.182 & 0.52 & -1.28 to 2.31 & 0.572 \\
\hline ACQ & -4.26 & -4.80 to -3.71 & $<0.0001$ & -2.57 & -3.34 to -1.81 & $<0.0001$ \\
\hline ICS & -3.04 & -3.63 to -2.43 & $<0.0001$ & -1.11 & -1.87 to -0.35 & 0.004 \\
\hline OCS & -8.30 & -10.6 to -5.99 & $<0.0001$ & -2.74 & -5.59 to 0.11 & 0.060 \\
\hline BEC & -0.0017 & -0.0031 to -0.0002 & 0.022 & 0.001 & -0.003 to 0.004 & 0.756 \\
\hline BNC & -0.0004 & -0.0006 to -0.0002 & $<0.0001$ & -0.0002 & -0.001 to -0.00003 & 0.048 \\
\hline SEC & -0.13 & -0.17 to -0.09 & $<0.0001$ & -0.08 & -0.14 to -0.02 & 0.007 \\
\hline SNC & -0.02 & -0.05 to 0.004 & 0.102 & -0.03 & -0.07 to 0.001 & 0.060 \\
\hline FeNO & -0.13 & -0.84 to -0.57 & 0.705 & 0.31 & -0.55 to 1.16 & 0.481 \\
\hline Exacerbations & -1.54 & -2.07 to -0.99 & $<0.0001$ & 0.03 & -0.67 to 0.74 & 0.922 \\
\hline Disease duration & -0.15 & -0.19 to -0.096 & $<0.0001$ & -0.23 & -0.29 to -0.17 & $<0.0001$ \\
\hline Hospitalizations & -4.35 & -5.74 to -2.96 & $<0.0001$ & -2.04 & -3.81 to -0.26 & 0.024 \\
\hline
\end{tabular}

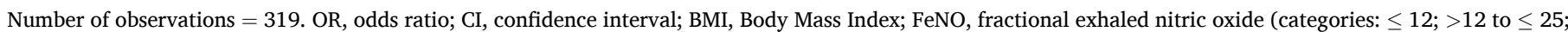

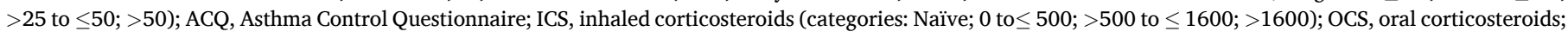
BEC, blood eosinophil count; BNC, blood neutrophil count; SEC, sputum eosinophil count; SNC, sputum neutrophil count.

and sputum eosinophils are associated with IRAO. We also found that total TGF- $\beta$ levels were significantly higher in IRAO.

There were significantly more ex-smokers in the IRAO group. Smoking was also a risk factor for IRAO and responsible for a decrease in the $\mathrm{FEV}_{1} / \mathrm{FVC}$ ratio in the multivariable analyses, and seems to be a major risk factors for IRAO [9,26,27]. Cigarette exposure is responsible for neutrophilic inflammation and neutrophil apoptosis leading to damage-associated molecular pattern (DAMPs), which may amplify smoking induced airway inflammation [28,29]. Due to this neutrophilic inflammation in smokers or changes in glucocorticoid receptor sensitivity, treatment regimens for smoking asthma require higher doses of inhaled corticosteroids [30]. Cigarette smoking also contributes to severity and exacerbations. This might explain why sputum neutrophil count, ICS doses and OCS therapy were not independently associated to IRAO anymore in the never smoker population. One might be tempted to assume IRAO is simply due to smoking habit in our IRAO population.
However, the sub-analysis on never smokers with IRAO confirmed that ACQ score, sputum eosinophils and disease duration are also associated with irreversible airway obstruction. According to guidelines [31], it is required to treat comorbidities such as smoking habit in order to prevent lung function decline in asthma. Since therapy for remodeling is not on the market yet, this study adds evidence to the fact that quitting smoking is clearly a first step to help these patients.

Patients presenting with neutrophilic inflammation represent only one quarter of our study population while $50 \%$ had an eosinophilic phenotype. These rates are similar to what has been reported in severe asthma [32] that can be defined by $\mathrm{FEV}_{1}<80 \%$ predicted. In our study IRAO occurred almost twice more often in patients with increased percentages of sputum eosinophils. Eosinophilic airway inflammation has the potential to induce airway remodeling [33] and is present in $41 \%$ of a general population of asthmatics [34]. We previously found that patients exhibiting elevated blood and sputum eosinophils were 


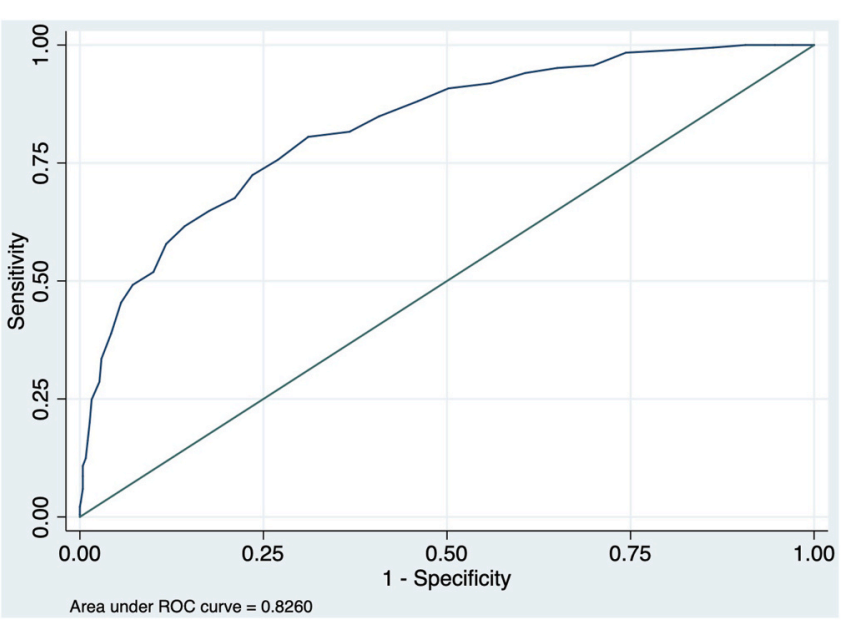

Fig. 2. ROC curve showing the best cut-off of ACQ score to identify IRAO in asthma. Sensitivity 72\%, specificity 77\%, cut-off: $2.36, \mathrm{p}<0.0001$, AUC: 0.8260 .

\section{TGF- $\beta$ in IRAO vs RAO}

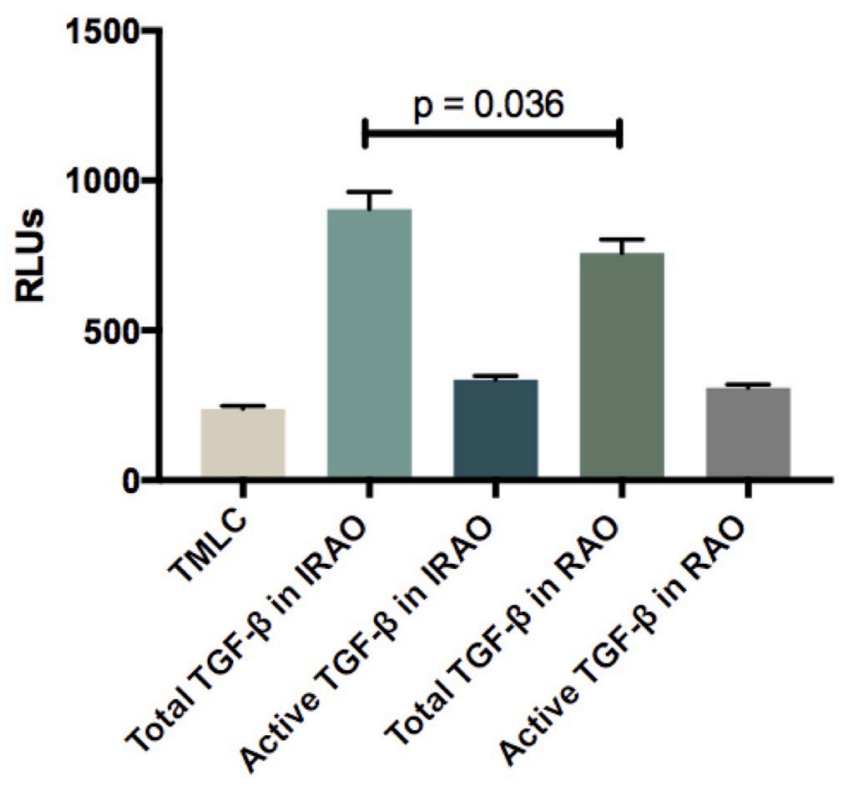

Fig. 3. Comparison of (total and active) TGF- $\beta$ levels in IRAO and RAO. RAO, Reversible airway obstruction; IRAO, irreversible airway obstruction.

characterized by poorer lung function [35]. In our study, blood eosinophil count was not associated with IRAO. Indeed, eosinophils must be attracted into the airways to induce remodeling [35]. Moreover, sputum eosinophil but not blood eosinophil counts were predictors of improvement of lung function with anti-IL5 therapy in severe eosinophilic asthmatics [36]. Eosinophils are the main source of TGF- $\beta$, a cytokine with profibrotic properties. We confirmed Cianchetti [37]'s results showing that TGF- $\beta$ identified a subgroup of severe asthmatic patients with IRAO. In studies evaluating efficacy of Mepolizumab (Anti-IL5), they found TGF- $\beta$ expression in eosinophils and signs of airway remodeling are reduced in parallel [38]. TGF- $\beta$ is one of the main factors implicated in airway remodeling in asthma. We found that total TGF- $\beta$ levels were significantly higher in IRAO. Only a small fraction of TGF- $\beta$ were biologically active in our samples and did not differ between groups. What differed was the pool of latent TGF- $\beta$ as total TGF- $\beta$ (which represent the active and latent TGF- $\beta$ ) was significantly different. The airways may serve as a reservoir of latent TGF- $\beta$ in the condition of IRAO representing a pool of "utilizable" TGF- $\beta$ insuring a ready source for local activation. Indeed, TGF- $\beta$ in the latent complex is the predominant form of the molecule and was shown to possess an extended plasma half-life compared with active TGF- $\beta$ [39].

To our knowledge, this is the first report using this gene reporter assay in a context of IRAO and sputum samples.

Though a higher ACQ score is certainly a consequence of IRAO, we think it is interesting to mention that IRAO can be suspected in a patient with a poor asthma control. Indeed, remodeling induces reduction in airflow calibre, and more asthma symptoms [5]. ACQ score can be obtained easily and could be very useful for general practitioners to perform in order to find out if the patient is presenting with IRAO (cut-off point of 2.36) in which case, IRAO can be suspected and this patient must be sent to a pulmonologist to exclude residual type 2 inflammation in the absence of which overtreatment with ICS can be avoided [40]. As previously shown, men have a higher risk of being IRAO than women $[14,27,41]$. Indeed, males tend to present with fewer symptoms, are poorer perceivers, despite active eosinophilic inflammation, thus tend to be less compliant to their medication [42]. Not surprisingly, disease duration is associated with IRAO [9].

One limitation of this study is that we based our definition of IRAO on BTS [43]/NICE [44] guidelines. Using the lower limit of normal (LLN) $\mathrm{FEV}_{1} / \mathrm{FVC}$ ratio reduces the misclassification of airway obstruction [45]. Unfortunately, visits prior 2018 did not include LLN values in our database. Since we purposely eliminated patients that did not fit in either IRAO nor RAO group, our patients in the IRAO group are truly asthmatics with persistent airway obstruction characteristics. As a tertiary care centre, the prevalence of IRAO might have been overestimated in our study.

\section{Conclusion}

We were able to show many risk factors independently associated to IRAO all together, previously mentioned separately in different studies. Risk factors for IRAO in a general population of asthmatics are male gender, smoking, a longer disease duration, uncontrolled asthma, eosinophilic or neutrophilic airway inflammation, lower BMI, and later asthma onset. Not surprisingly, sputum eosinophils are biomarkers for remodeling as they reflect local inflammation as opposed to blood eosinophils which reflect systemic inflammation. Moreover, TGF- $\beta$ levels are higher in IRAO.

\section{Disclosure}

Dr. LOUIS reports grants and personal fees from GSK, grants and personal fees from AZ, grants and personal fees from Novartis, grants from Chiesi, outside the submitted work. The other authors declare no conflict of interest related to this paper.

\section{Funding}

This work was supported by the European Union (Interreg EMR Muse Rhine 5a) and Interuniversity Attraction Poles Program.

\section{Declaration of competing interest}

The authors declare that they have no known competing financial interests or personal relationships that could have appeared to influence the work reported in this paper.

\section{Acknowledgements}

We thank Prof. Daniel Rifkin, New York University medical center, NY, for the gift of Transformed mink lung cells (TMLC). 


\section{Appendix A. Supplementary data}

Supplementary data related to this article can be found at https://do i.org/10.1016/j.rmed.2020.106202.

\section{References}

[1] J.K. Peat, A.J. Woolcock, K. Cullen, Rate of decline of lung function in subjects with asthma, Eur. J. Respir. Dis. 70 (1987) 171-179.

[2] P. Lange, J. Parner, J. Vestbo, P. Schnohr, G. Jensen, A 15-year follow-up study of ventilatory function in adults with asthma, N. Engl. J. Med. 339 (1998) 1194-1200.

[3] S. Graff, S. Demarche, M. Henket, V. Paulus, R. Louis, F. Schleich, Increase in blood eosinophils during follow-up is associated with lung function decline in adult asthma, Respir. Med. (2019) 60-66.

[4] T.R. Bai, D.A. Knight, Structural changes in the airways in asthma: observations and consequences, Clin. Sci. 108 (2005) 463-477.

[5] H. Fehrenbach, C. Wagner, M. Wegmann, Airway remodeling in asthma: what really matters, Cell Tissue Res. 367 (2017) 551-569.

[6] C. Hudson, H. Turcotte, M. Laviolette, G. Carrier, L.-P. Boulet, Characteristics of bronchial asthma with incomplete reversibility of airflow obstruction, Ann. Allergy Asthma Immunol. 78 (1997) 195-202.

[7] C.I. Panhuysen, J.M. Vonk, G.H. Koëter, J.P. Schouten, R. van Altena, E. R. Bleecker, D.S. Postma, Adult patients may outgrow their asthma: a 25-year follow-up study, Am. J. Respir. Crit. Care Med. 155 (4) (1997 Apr) 1267-1272, https://doi.org/10.1164/ajrccm.155.4.9105065. PubMed PMID: 9105065.

[8] C.S. Ulrik, V. Backer, Nonreversible airflow obstruction in life-long nonsmokers with moderate to severe asthma, Eur. Respir. J. 14 (1999) 892-896.

[9] L. Zhang, L. He, J. Gong, C. Liu, Risk factors associated with irreversible airway obstruction in asthma: a systematic review and meta-analysis, Biomed. Res. Int. (2016), 2016Available from: https://www.ncbi.nlm.nih.gov/pmc/articles/PM C4828538/.

[10] D. Bumbacea, D. Campbell, L. Nguyen, D. Carr, P.J. Barnes, D. Robinson, K. F. Chung, Parameters associated with persistent airflow obstruction in chronic severe asthma, Eur. Respir. J. 24 (2004) 122-128.

[11] P. Sexton, P. Black, L. Wu, F. Sommerville, M. Hamed, P. Metcalf, J. Kolbe, Fixed airflow obstruction among nonsmokers with asthma:A case-comparison study, J. Asthma 50 (2013) 606-612.

[12] J.H. Lee, T. Haselkorn, L. Borish, L. Rasouliyan, B.E. Chipps, S.E. Wenzel, Risk factors associated with persistent airflow limitation in severe or difficult-to-treat asthma: insights from the TENOR study, Chest 132 (2007) 1882-1889.

[13] K. Mascia, T. Haselkorn, Y.M. Deniz, D.P. Miller, E.R. Bleecker, L. Borish, Aspirin sensitivity and severity of asthma: evidence for irreversible airway obstruction in patients with severe or difficult-to-treat asthma, J. Allergy Clin. Immunol. 116 (2005) 970-975.

[14] A. ten Brinke, A.H. Zwinderman, P.J. Sterk, K.F. Rabe, E.H. Bel, Factors associated with persistent airflow limitation in severe asthma, Am. J. Respir. Crit. Care Med. 164 (2001) 744-748.

[15] A.-S. Jang, J.-S. Park, J.-H. Lee, S.-W. Park, D.-J. Kim, S.-T. Uh, Y.-H. Kim, C. S. Park, Asthmatics without rhinitis have more fixed airway obstruction than those with concurrent rhinitis, Allergy Asthma Immunol. Res. 2 (2010) 108.

[16] P.K. Jeffery, Remodeling and inflammation of bronchi in asthma and chronic obstructive pulmonary disease, Proc. Am. Thorac. Soc. 1 (2004) 176-183.

[17] J.C. Hogg, F. Chu, S. Utokaparch, R. Woods, W.M. Elliott, L. Buzatu, R. M. Cherniack, R.M. Rogers, F.C. Sciurba, H.O. Coxson, P.D. Paré, The nature of small-airway obstruction in chronic obstructive pulmonary disease, N. Engl. J. Med. 350 (2004) 2645-2653.

[18] K.F. Chung, I.M. Adcock, Multifaceted mechanisms in COPD: inflammation, immunity, and tissue repair and destruction, Eur. Respir. J. 31 (2008) 1334-1356.

[19] L. Godinas, J.-L. Corhay, M. Henket, J. Guiot, R. Louis, C. Moermans, Increased production of TGF- $\beta 1$ from sputum cells of COPD: relationship with airway obstruction, Cytokine 99 (2017) 1-8.

[20] E.F. Juniper, G.H. Guyatt, R.S. Epstein, P.J. Ferrie, R. Jaeschke, T.K. Hiller, Evaluation of impairment of health related quality of life in asthma: development of a questionnaire for use in clinical trials, Thorax 47 (1992) 76-83.

[21] E.F. Juniper, P.M. O' byrne, G.H. Guyatt, P.J. Ferrie, D.R. King, Development and validation of a questionnaire to measure asthma control, Eur. Respir. J. 14 (1999) 902-907.

[22] M. Schatz, C.A. Sorkness, J.T. Li, P. Marcus, J.J. Murray, R.A. Nathan, M. Kosinski, T.B. Pendergraft, P. Jhingran, Asthma Control Test: reliability, validity, and responsiveness in patients not previously followed by asthma specialists, J. Allergy Clin. Immunol. 117 (2006) 549-556.

[23] R.A. Dweik, P.B. Boggs, S.C. Erzurum, C.G. Irvin, M.W. Leigh, A.-C. Olin, A. L. Plummer, R.D. Taylor, An official ATS clinical practice guideline: interpretation of exhaled nitric oxide levels (FENO) for clinical applications, Am. J. Respir. Crit. Care Med. 184 (2011) 602-615.
[24] J. Guiot, S. Demarche, M. Henket, V. Paulus, S. Graff, F. Schleich, J.-L. Corhay, R. Louis, C. Moermans, Methodology for sputum induction and laboratory processing, Journal of Visualized Experiments (2019) [Internet] 2017 [cited 2019 Dec 9]; Available from: https://www.jove.com/video/56612/methodology-fo $r$-sputum-induction-and-laboratory-processing.

[25] R. Louis, L. Godinas, F. Schleich, Induced Sputum - towards Normal Values, Non Invasive Assessment of Airways Inflammation in Asthma and COPD. 14th, Tetrapoleos Street, 115 27, Paschalidis Medical Publications, Athens, 2011. Greece.

[26] M. Contoli, S. Baraldo, B. Marku, P. Casolari, J.A. Marwick, G. Turato, M. Romagnoli, G. Caramori, M. Saetta, L.M. Fabbri, A. Papi, Fixed airflow obstruction due to asthma or chronic obstructive pulmonary disease: 5-year followup, J. Allergy Clin. Immunol. 125 (2010) 830-837.

[27] COhort for Reality and Evolution of adult Asthma in Korea study group (COREA study group), T. Lee, Y.S. Lee, Y.-J. Bae, T.-B. Kim, S.O. Kim, S.-H. Cho, H.-B. Moon, Y.S. Cho, Smoking, longer disease duration and absence of rhinosinusitis are related to fixed airway obstruction in Koreans with severe asthma: findings from the COREA study, Respir. Res. 12 (2011) 1.

[28] I.H. Heijink, S.D. Pouwels, C. Leijendekker, H.G. de Bruin, G.J. Zijlstra, H. van der Vaart, N.H.T. ten Hacken, A.J.M. van Oosterhout, M.C. Nawijn, M. van der Toorn, Cigarette smoke-induced damage-associated molecular pattern release from necrotic neutrophils triggers proinflammatory mediator release, Am. J. Respir. Cell Mol. Biol. 52 (2015) 554-562.

[29] X. Huang, X. Tan, Y. Liang, C. Hou, D. Qu, M. Li, Q. Huang, Differential DAMP release was observed in the sputum of COPD, asthma and asthma-COPD overlap (ACO) patients, Sci. Rep. 9 (2019) 19241.

[30] N.C. Thomson, Asthma and cigarette smoking, Eur. Respir. J. 24 (2004) 822-833.

[31] K.F. Chung, S.E. Wenzel, J.L. Brozek, A. Bush, M. Castro, P.J. Sterk, I.M. Adcock, E. D. Bateman, E.H. Bel, E.R. Bleecker, L.-P. Boulet, C. Brightling, P. Chanez, S.E. Dahlen, R. Djukanovic, U. Frey, M. Gaga, P. Gibson, Q. Hamid, N.N. Jajour, T. Mauad, R.L. Sorkness, W.G. Teague, International ERS/ATS guidelines on definition, evaluation and treatment of severe asthma, Eur. Respir. J. 43 (2014) 343-373.

[32] F. Schleich, G. Brusselle, R. Louis, O. Vandenplas, A. Michils, C. Pilette, R. Peche, M. Manise, G. Joos, Heterogeneity of phenotypes in severe asthmatics. The Belgian severe asthma registry (BSAR), Respir. Med. 108 (2014) 1723-1732.

[33] H.H. Kariyawasam, D.S. Robinson, The role of eosinophils in airway tissue remodelling in asthma, Curr. Opin. Immunol. 19 (2007) 681-686.

[34] F.N. Schleich, M. Manise, J. Sele, M. Henket, L. Seidel, R. Louis, Distribution of sputum cellular phenotype in a large asthma cohort: predicting factors for eosinophilic vs neutrophilic inflammation, BMC Pulm. Med. 13 (2013) 11.

[35] F.N. Schleich, A. Chevremont, V. Paulus, M. Henket, M. Manise, L. Seidel, R. Louis, Importance of concomitant local and systemic eosinophilia in uncontrolled asthma, Eur. Respir. J. 44 (2014) 97-108.

[36] F. Schleich, S. Graff, H. Nekoee, C. Moermans, M. Henket, C. Sanchez, V. Paulus, F. Guissard, A. Donneau, R. Louis, Real-word experience with mepolizumab: does it deliver what it has promised? Clin. Exp. Allergy 50 (2020) 687-695.

[37] S. Cianchetti, C. Cardini, I. Puxeddu, M. Latorre, M.L. Bartoli, M. Bradicich, F. Dente, E. Bacci, A. Celi, P. Paggiaro, Distinct profile of inflammatory and remodelling biomarkers in sputum of severe asthmatic patients with or without persistent airway obstruction, World Allergy Org. J. 12 (2019) 100078.

[38] P.T. Flood-Page, A.N. Menzies-Gow, A.B. Kay, D.S. Robinson, Eosinophil's role remains uncertain as anti-interleukin-5 only partially depletes numbers in asthmatic airway, Am. J. Respir. Crit. Care Med. 167 (2003) 199-204.

[39] L.M. Wakefield, T.S. Winokur, R.S. Hollands, K. Christopherson, A.D. Levinson, M. B. Sporn, Recombinant latent transforming growth factor beta 1 has a longer plasma half-life in rats than active transforming growth factor beta 1 , and a different tissue distribution, J. Clin. Invest. 86 (1990) 1976-1984.

[40] S. Demarche, F. Schleich, M. Henket, V. Paulus, R. Louis, T. Van Hees, Step-down of inhaled corticosteroids in non-eosinophilic asthma: a prospective trial in real life, Clin. Exp. Allergy 48 (2018) 525-535.

[41] J. Liebhart, M. Polak, A. Dabrowski, R. Dobek, E. Liebhart, A. Dor-Wojnarowska, W. Barg, A. Kulczak, W. Medrala, U. Gladysz, A. Lange, The G/G genotype of transforming growth factor beta 1 (TGF- $\beta 1$ ) single nucleotide $(+915 \mathrm{G} / \mathrm{C})$ polymorphism coincident with other host and environmental factors is associated with irreversible bronchoconstriction in asthmatics, Int. J. Immunogenet. 35 (2008) 417-422.

[42] P. Haldar, I.D. Pavord, D.E. Shaw, M.A. Berry, M. Thomas, C.E. Brightling, A. J. Wardlaw, R.H. Green, Cluster analysis and clinical asthma phenotypes, Am. J. Respir. Crit. Care Med. 178 (2008) 218-224.

[43] BTS guidelines for the management of chronic obstructive pulmonary disease, Thorax 52 (1997) 1-28.

[44] National Institute for Clinical Excellence, Clinical Guideline 12. Chronic Obstructive Pulmonary Disease February 2004, accessed, www.nice.org.uk /CG012NICEguideline. (Accessed 3 October 2008).

[45] M.P. Swanney, G. Ruppel, P.L. Enright, O.F. Pedersen, R.O. Crapo, M.R. Miller, R. L. Jensen, E. Falaschetti, J.P. Schouten, J.L. Hankinson, J. Stocks, P.H. Quanjer, Using the lower limit of normal for the FEV1/FVC ratio reduces the misclassification of airway obstruction, Thorax 63 (2008) 1046-1051. 